\title{
HEIGHTS AND WEIGHTS OF MEN VISITING A PUBLIC HEALTH EXHIBITION
}

\author{
R. E. WALLER AND A. G. F. BROOKS \\ MRC Air Pollution Unit, St. Bartholomew's Hospital Medical College, London E.C.I
}

Although height and weight are the most commonly measured parameters in clinical and preventive medicine, there have been surprisingly few studies of their distribution in adult populations. Khosla and Lowe (1968) have published an analysis of height and weight measurements made during the course of their surveys of industrial populations, comparing the results with those of earlier studies in the United Kingdom. Their results indicated a continuation of the secular increase in heights that had been observed for many decades, and they provided evidence of a rapid increase in weights also. The substantial change in weight in relation to height was considered to be of major importance, in view of the well established relationship between body weight and mortality from cardiovascular disease.

More recently, Khosla and Lowe (1971) have analysed their results in relation to smoking habits, pointing out that while smoking increases the risk of death from coronary disease, people who give up smoking tend to put on weight, thereby increasing this same risk through obesity. In view of the current interest in this topic and the general interest in long-term trends in height and weight, we present here an analysis of measurements made at a public health exhibition in the City of London in April 1970 among a population consisting mainly of office workers. These measurements were made primarily to allow us to standardize the results of peak flow measurements made at the same time (Brooks and Waller, 1972). The present paper is limited to results from the 2,169 men in the sample.

\section{Material AND Methods}

The exhibition, entitled 'Good Health', was held in April 1970 in a permanent hall frequented by lunch-time crowds from adjoining office blocks in the City of London. There was obviously a risk of attracting 'health-conscious' subjects, but most people entered merely as a diversion in the lunchhour, and there was little indication of the scope of the exhibition outside the hall. Everyone who came in during the lunch-time period for the five weeks of the exhibition was invited to take part and the majority agreed. The subjects were asked when and where they were born, where they lived, and details of their smoking habits. They were then weighed on portable bathroom scales and their heights were measured on a wooden measuring stand. The men kept their shoes on, and one inch was deducted from the heights to allow for this. Heights were recorded to the nearest inch and weights, including light indoor clothing, to the nearest pound, but the units were changed to centimetres and kilogrammes before analysis of the results. Some of the subjects came from a nearby college of further education, and to increase the number of teenagers in th 8 sample the survey was continued in further lunche time sessions at the college itself.

\section{HeIGHT Results}

Figure 1 shows that height decreased slowly with increasing age : individuals may 'shrink' a little as they grow older, but the observed trend is usually interpreted as a cohort effect, with each successive birth cohort attaining slightly greater mean heights than its predecessors (Khosla and Lowe, 1968).

In our study men born in 1940 (aged 30 when seen) were $4 \mathrm{~cm}$ taller than those born in 1910 . This secular increase in height of just over $1 \mathrm{~cm}$

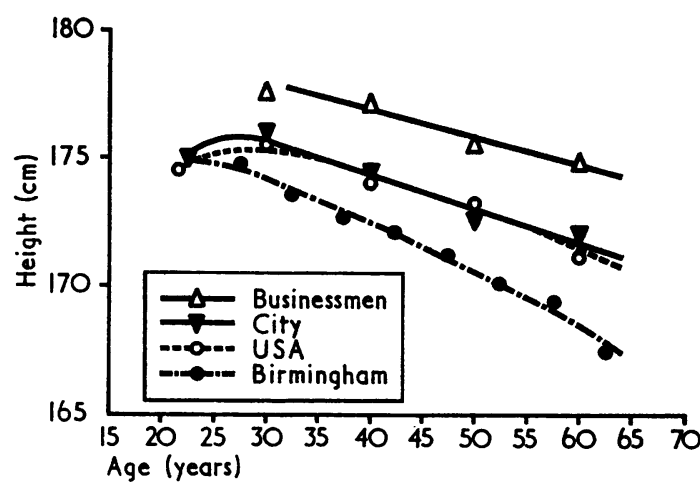

FIG. 1-Mean height in relation to age, males. 
( 0.5 in) per decade is the same as that quoted by Khosla and Lowe (1968) from a study of several other British samples. The differences between successive means are significant, even in the case of the apparent small increase in height in the twenties. An important point to consider in this connection is whether the social class bias in our sample is the same in all age groups. Khosla and Lowe (1967) found a difference in height according to 'work status' in their sample of men measured at a Birmingham factory in 1960 , monthly paid staff being the tallest. The results for their whole sample (Khosla and Lowe, 1968) are shown in Figure 1. In the age range 20-24, the mean height of our sample is the same as that of the Birmingham factory workers, but in other age groups the mean heights in our series are 1 to $2 \mathrm{~cm}$ greater. Since at any given age members of our sample would have been born 10 years later than the corresponding Birmingham men, a difference of about $1 \mathrm{~cm}$ would be expected from the secular increase alone, and the remaining very small differences between the curves might be explicable in terms of differences in social class. We did not enquire into the status of visitors to the exhibition, but they included the Lord Mayor, members of the Corporation, and other City executives in the upper age ranges. The lower age ranges included a larger proportion of weekly paid workers who would not necessarily stay in the City in later life. It is possible that the sample in the early twenties was biassed by the absence of people still pursuing full-time education and this may have affected results. A group of medical students seen earlier (Lawther, Brooks, and Waller, 1970) were $4 \mathrm{~cm}$ taller than members of the City sample aged 20-24, and the part-time students (aged 15-19) in the present study were about $1 \mathrm{~cm}$ taller than the rest of the sample in that age range.

A further comparison can be made with results from a sample of businessmen measured during the 1960s (Richardson and Pincherle, 1969). These are shown in the upper curve in Figure 1, and the means are about $2 \mathrm{~cm}$ above those in our series. Since the businessmen were seen several years earlier than the members of our sample, any secular increase would tend to enhance the difference, and it is likely to be due to the fact that the businessmen were all social class I. Results are available from a national sample measured in the United States in 1960-62 (Stoudt, Damon, McFarland, and Roberts, 1965). These closely resemble ours (Figure 1) but, allowing for the secular change in height, the men in our sample would be about $1 \mathrm{~cm}$ shorter than Americans of corresponding birth dates.
TABLE I

MEAN HEIGHTS AND WEIGHTS BY AGE, WITH REGRESSION COEFFICIENT OF WEIGHT ON HEIGHT

\begin{tabular}{|c|c|c|c|c|}
\hline $\begin{array}{c}\text { Age } \\
\text { Range }\end{array}$ & $\begin{array}{l}\text { No. of } \\
\text { Subjects }\end{array}$ & $\underset{\text { cm }(\bar{x})}{\text { Mean Ht. }}$ & $\underset{\text { kg }(\bar{y})}{\operatorname{Mean} W t .}$ & $\begin{array}{l}\text { Regression coeff. } \\
b \text { and S.E. }\end{array}$ \\
\hline $\begin{array}{l}15-19 \\
20-24 \\
25-34 \\
35-44 \\
45-54 \\
55-64 \\
65+\end{array}$ & $\begin{array}{r}269 \\
438 \\
524 \\
364 \\
308 \\
207 \\
42\end{array}$ & $\begin{array}{l}172 \cdot 9 \\
174 \cdot 8 \\
176 \cdot 0 \\
174 \cdot 4 \\
172 \cdot 8 \\
171 \cdot 8 \\
171 \cdot 2\end{array}$ & $\begin{array}{l}65 \cdot 1 \\
69 \cdot 5 \\
73 \cdot 0 \\
75 \cdot 5 \\
75 \cdot 6 \\
74 \cdot 6 \\
72 \cdot 6\end{array}$ & $\begin{array}{l}0.79 \pm 0.07 \\
0.70 \pm 0.06 \\
0.75 \pm 0.05 \\
0.76 \pm 0.06 \\
0.70 \pm 0.07 \\
0.84 \pm 0.08 \\
0.91 \pm 1.15\end{array}$ \\
\hline
\end{tabular}

\section{WEIGHTS}

Among our subjects mean weight (Table I) gradually increases to a maximum around age 45 , and then falls with increasing age. These variations are, however, confounded with differences in height, and are better considered in terms of weight at fixed height. A standardization procedure was therefore developed in the same way as for the peak flow measurements in this series (Brooks and Waller, 1972). The differences between the regression coefficients of weight on height at different ages (Table I) are small and not significant statistically, and the mean of these was therefore used to standardize weights. Each individual's weight was adjusted to the equivalent value at a height of 174 $\mathrm{cm}$ (the mean in this series) by using the following formula:

$$
W_{\mathrm{s}}=W-0.75(h-174)
$$

where $W$ is the observed weight $(\mathrm{kg}), h$ is the observed height $(\mathrm{cm})$, and $W_{\mathrm{s}}$ is the standardized weight. The coefficient 0.75 is the weighted mean of the regression coefficients in Table I. The regression of weight on height for all ages combined was also calculated, but the coefficient obtained was not used for standardization purposes because of cohort effects in the distribution of heights. In a recent study in Norway, Bjelke (1971) has also found that the regression of weight on height is independent of age.

In our series height-standardized weight increases rapidly with age (Figure 2) up to the mid-fifties and then falls. The differences between successive means are large and statistically significant up to age 45 but small and non-significant beyond that. Results from other series included for comparison in this diagram have been adjusted to the same standard height $(174 \mathrm{~cm})$ either from the weight-for-height data within each study or by using our own formula. Differences in the weight of clothes included in the measurements may account for some small differences in absolute values between the series : in our case we estimated that the clothes worn (including 

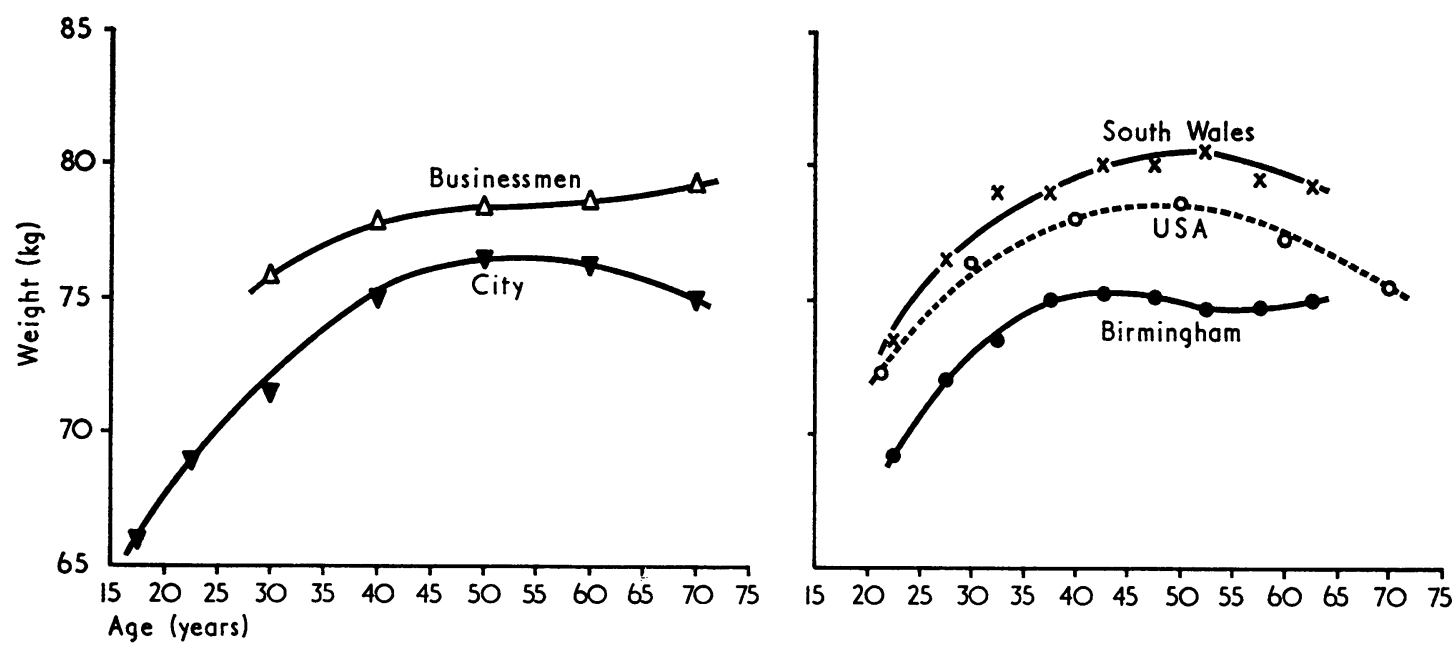

Fig. 2-Weight in relation to age, males (adjusted to standard height of $174 \mathrm{~cm}$ ).

shoes) weighed about $3 \mathrm{~kg}$. The men in our series were very similar in weight to those in the Birmingham sample up to age 40 , but they were a little heavier in the fifties. Our upper age ranges contained a substantial proportion of businessmen, and the sample of businessmen alone (Richardson and Pincherle, 1969) was heavier at all ages. Khosla and Lowe (1968) found that men measured at a South Wales steel works in 1965 were heavier, in relation to their height, than those in the Birmingham sample measured in 1960 . These findings, when linked with earlier measurements made among working populations, indicated a secular increase in obesity extending at least from 1930 to 1965 . Repeated studies within the same type of population would be required to establish whether this trend is continuing. From our results we can only say that the City workers measured in 1970 were, in terms of obesity, within the range of other samples measured in the 1960s. The curve for the national American sample measured in 1960-62 (Stoudt et al., 1965) lies between those for our City 1970 sample and the South Wales 1965 sample, the American men being 2 to $4 \mathrm{~kg}$ heavier than the City men up to middle age but only marginally heavier in old age.

A weight-for-height table has been constructed from our data (Table II) for comparison with the findings of Khosla and Lowe (1968), and for this particular purpose our figures have been converted back to pounds and inches. These figures have been obtained by reading weights at a height of $174 \mathrm{~cm}$ from the curve in Figure 2 and applying our height adjustment formula to obtain expected values at other heights. In the top right-hand corner of the
TABLE II

BODY WEIGHT PER INCH OF STANDING HEIGHT: MALES, LONDON, 1970

\begin{tabular}{|c|c|c|c|c|c|c|c|}
\hline \multirow{2}{*}{$\begin{array}{l}\text { Height } \\
\text { (in) }\end{array}$} & \multicolumn{7}{|c|}{ Weight (lb) at Age: } \\
\hline & $15-19$ & $20-24$ & $25-29$ & $30-34$ & $35-39$ & $40-44$ & $45-6$ \\
\hline $\begin{array}{l}62 \\
63 \\
64 \\
65 \\
66 \\
67 \\
68 \\
69 \\
70 \\
71 \\
72 \\
73 \\
74\end{array}$ & $\begin{array}{l}118 \\
122 \\
127 \\
131 \\
135 \\
139 \\
143 \\
148 \\
152 \\
156 \\
160 \\
164 \\
169\end{array}$ & $\begin{array}{l}124 \\
128 \\
132 \\
137 \\
141 \\
145 \\
149 \\
154 \\
158 \\
162 \\
166 \\
170 \\
174\end{array}$ & $\begin{array}{l}129 \\
133 \\
138 \\
142 \\
146 \\
150 \\
154 \\
158 \\
163 \\
167 \\
171 \\
175 \\
180\end{array}$ & $\begin{array}{l}133 \\
138 \\
142 \\
146 \\
150 \\
154 \\
158 \\
163 \\
167 \\
171 \\
175 \\
180 \\
184\end{array}$ & $\begin{array}{l}137 \\
141 \\
145 \\
149 \\
154 \\
158 \\
162 \\
166 \\
170 \\
174 \\
179 \\
183 \\
187\end{array}$ & $\begin{array}{l}139 \\
143 \\
148 \\
152 \\
156 \\
160 \\
164 \\
168 \\
173 \\
177 \\
181 \\
185 \\
190\end{array}$ & $\begin{array}{l}141 \stackrel{0}{\supset} \\
145 \\
149 \\
153 \\
158 \\
162 \\
166 \\
170 \\
174 \\
178 \\
183 \\
187 \\
191\end{array}$ \\
\hline
\end{tabular}

Weights include light indoor clothes and shoes (approximately $7 \mathrm{lb}$ in all), but heights are quoted without shoes.

table (i.e., for short older men) the figures are very $\dot{0}$ similar to those of Khosla and Lowe (1968), but the differences increase towards the bottom left-hand $\delta$ corner, and for tall young men our figures, based $₹$ primarily on London office workers, are about 을 $14 \mathrm{lb}(6 \mathrm{~kg})$ lighter than those based on the South Wales steel-workers. Clearly, differences of this type will arise between various sets of data from specific populations, and in this case they may or indicate differences in muscular development and $N$ general body build rather than in obesity.

\section{Weight In RELATION to SMOKING}

Differences in mean weights for non-smokers, ex-smokers and smokers were small and non- $\stackrel{\infty}{\rightleftharpoons}$ significant at all ages in this series (Table III). Khosla and Lowe (1971) found much larger differences in weight in relation to smoking in their 
TABLE III

HEIGHT-STANDARDIZED WEIGHT BY AGE AND SMOKING HABITS

\begin{tabular}{c|c|c|c}
\hline \multirow{2}{*}{$\begin{array}{c}\text { Age } \\
\text { Range }\end{array}$} & \multicolumn{3}{|c}{ Weight (kg): Mean and S.E. } \\
\cline { 2 - 4 } & Non-smokers & Ex-smokers & \multicolumn{1}{c}{ Smokers } \\
\hline & & & \\
$15-19$ & $65.9 \pm 0.8$ & $64.6 \pm 1.2$ & $66.1 \pm 0.6$ \\
$20-24$ & $68.7 \pm 0.6$ & $70.1 \pm 1.2$ & $68.8 \pm 0.5$ \\
$25-34$ & $71.8 \pm 0.6$ & $71.7 \pm 0.8$ & $71.4 \pm 0.6$ \\
$35-44$ & $75.0 \pm 0.7$ & $75.1 \pm 0.7$ & $75.3 \pm 0.7$ \\
$45-54$ & $77.2 \pm 1.0$ & $76.6 \pm 0.8$ & $76.0 \pm 0.8$ \\
$55-64$ & $77.7 \pm 1.2$ & $76.4 \pm 1.0$ & $75.4 \pm 0.9$ \\
$65+$ & $74.5 \pm 1.9$ & $75.1 \pm 3.2$ & $75.1 \pm 2.0$ \\
& & & \\
\hline
\end{tabular}

sample of steelworkers (Figure 3). In this comparison, smoking habits have been classified in three broad groups only. Our sample was not large enough to consider the effect of different types and amounts of smoking, but it may be important to note (Table IV) that an appreciable proportion of the smokers included in the City figures smoked pipes or cigars, and the average consumption of cigarettes per smoker was a little below that of the general population (as estimated from the figures of Todd (1969)).

Heights and weights were examined in relation to place of birth, within 10-year age groups, but differences between London-born subjects and others were small and in general not statistically significant. Similarly, there were no consistent differences in relation to area of present home.
TABLE IV

PERCENTAGE OF SMOKERS AND MEAN DAILY CIGARETTE CONSUMPTION

\begin{tabular}{|c|c|c|c|c|c|c|}
\hline \multirow[b]{2}{*}{$\begin{array}{c}\text { Age } \\
\text { Range }\end{array}$} & \multicolumn{4}{|c|}{ Percentage in Each Category } & \multicolumn{2}{|c|}{$\begin{array}{l}\text { Cigarettes/ } \\
\text { Smoker/Day }\end{array}$} \\
\hline & $\begin{array}{c}\text { Non- } \\
\text { smokers }\end{array}$ & $\begin{array}{c}\text { Ex- } \\
\text { smokers }\end{array}$ & $\begin{array}{l}\text { Pipes/ } \\
\text { cigars }\end{array}$ & Cigarettes & City & $\begin{array}{l}\text { General } \\
\text { Popn. }\end{array}$ \\
\hline $\begin{array}{c}16-19 \\
20-24 \\
25-29 \\
30-34 \\
35-49 \\
50-59 \\
60+\end{array}$ & $\begin{array}{l}40 \\
46 \\
42 \\
40 \\
38 \\
29 \\
25\end{array}$ & $\begin{array}{r}8 \\
12 \\
14 \\
20 \\
25 \\
31 \\
28\end{array}$ & $\begin{array}{r}2 \\
2 \\
7 \\
4 \\
9 \\
10 \\
12\end{array}$ & $\begin{array}{l}51 \\
41 \\
38 \\
36 \\
28 \\
31 \\
34\end{array}$ & $\begin{array}{l}13 \cdot 0 \\
13 \cdot 8 \\
14 \cdot 7 \\
14 \cdot 3 \\
16 \cdot 6 \\
16 \cdot 4 \\
17 \cdot 4\end{array}$ & $\begin{array}{l}15 \cdot 9 \\
18 \cdot 7 \\
18 \cdot 0 \\
19 \cdot 1 \\
20 \cdot 3 \\
19 \cdot 6 \\
14 \cdot 3\end{array}$ \\
\hline
\end{tabular}

In this table men who smoked pipes or cigars as well as cigarettes have been included with cigarette smokers, and the consumption of cigarettes is quoted per smoker of cigarettes or cigarettes plus pipes/cigars. Age ranges have been selected to match those for the general population (Todd, 1969).

\section{Discussion}

Although our sample was self-selected, the results of the analyses of height and weight measurements were in general agreement with those of other recent series. There have been few studies based on random samples of the whole adult population and it is difficult therefore to separate secular changes in height and weight from those attributable to differences in social class or ethnic characteristics. However, on the assumption that the heights of individuals change very little during adult life, the gradual decline in height with age seen within any one series can be interpreted as a cohort effect.
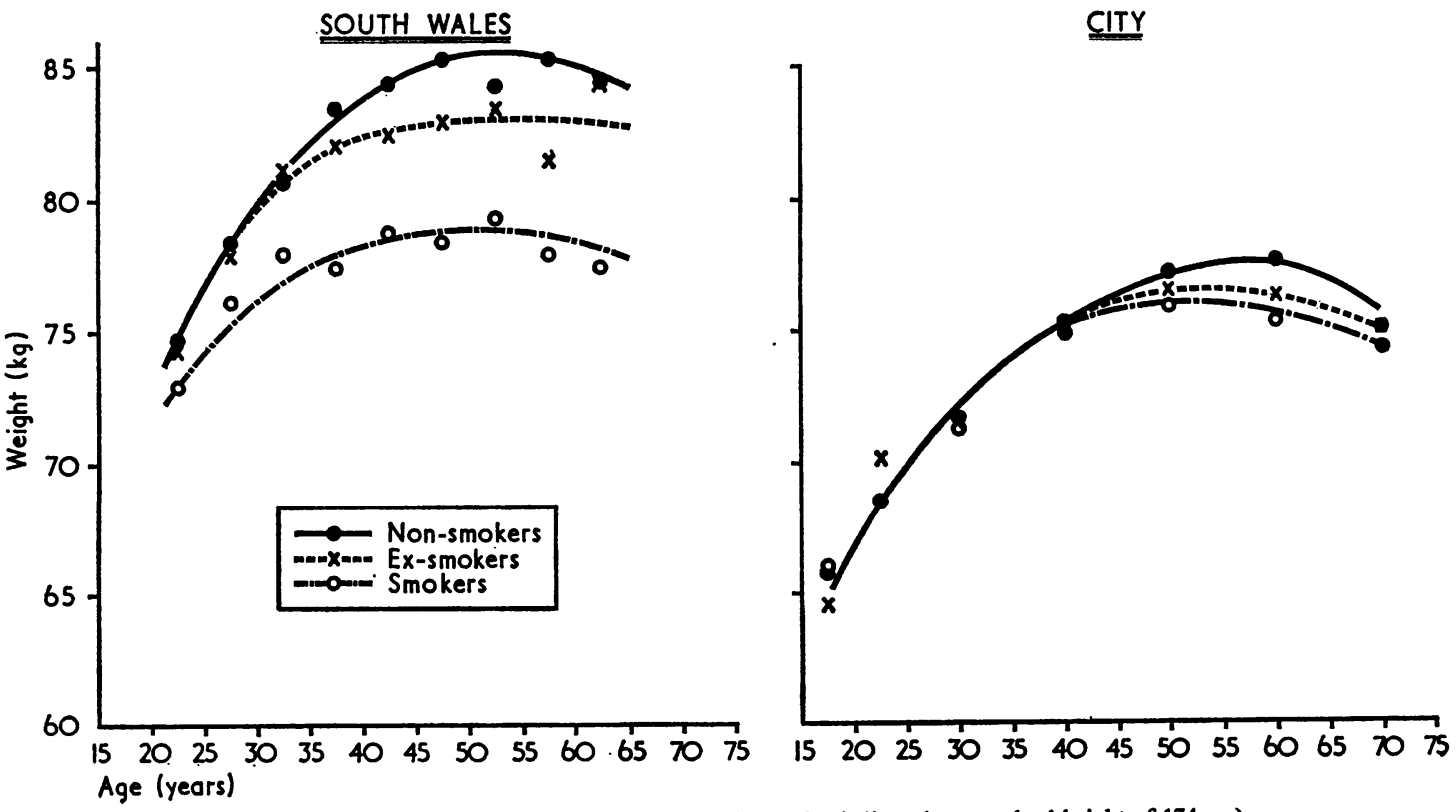

FrG, 3-Weight in relation to age and smoking habits, males (adjusted to standard height of $174 \mathrm{~cm}$ ). 
On this basis our results indicate a continuing secular increase in height of about $1 \mathrm{~cm}$ per decade, which is in close agreement with that from all other series that have been reported.

It is not possible to assess cohort effects on weight in this way, since they are completely obscured by changes in the weights of individuals with age. It is also difficult to draw conclusions on secular changes in weight by comparing results from samples studied some years apart, unless such samples are drawn from the same types of population.

To follow trends in weight with age, even within a single study, it is necessary to make some adjustment for differences in height. The procedure that we used, in which each individual's weight was adjusted to the equivalent value at a standard height, was easy to apply in the computer analysis of the results, and it enabled us to link height-standardized weights with the height-standardized peak flows that had been calculated in a similar manner (Brooks and Waller, 1972). Relative weight (the ratio of observed weight to that expected from a standard weight-for-height relationship) is sometimes used, and Benn (1971) has shown that there is an equivalence between this and indices of obesity, of the form weight/height ${ }^{p}$, used by other authors. The value of $p$ derived from our data is $1 \cdot 8$, the same as that calculated by Benn from earlier studies, and an index of the form weight/height $1 \cdot 8$ could be used as an alternative measure of 'obesity' within this population.

There was only a suggestion of a greater increase in weight with age among ex-smokers and men who had never smoked than among smokers. This is in contrast with the large differences reported by Khosla and Lowe (1971) from their study of Welsh steel-workers, and it is difficult to see how any degree of health-consciousness that might have affected the selection of people in our sample would have influenced the distribution of weight selectively with respect to smoking habits. There was not much difference in weight between smokers in the two series, but the non-smokers in the City sample were much lighter than the corresponding steel-workers. In this connection it must be emphasized that our subjects were nearly all office workers, and their lighter weights as compared with manual workers probably reflected differences in muscle rather than fat. Lowe (1971) has reported that within his sample of Birmingham factory workers seen in 1960, the differences in weight between smoking categories were similar to those seen in the Welsh study, and Ashford et al. (1961) found that among coal-miners non-smokers were heavier (and taller) than smokers.
Pincherle (1971) found little difference in the distribution of weights in relation to smoking habits in his study of businessmen, and he considered that weight gain was not an inevitable consequence of giving up smoking. Howell (1971), on the other hand, has reported differences in weight gain between men in various smoking categories, although these differences were small in comparison with those of Khosla and Lowe. This subject is of considerable importance in relation to anti-smoking campaigns, for it is often argued that the risk of weight gain on giving up smoking carries with it an increased liability to cardiovascular disease that is as great as that associated with continued smoking. It is possible that there is more concern with weight control in some sections of the community than in others, or that such concern has increased in recent years, and to investigate the situation more thoroughly there is a need for further longitudinal studies, in which changes in individuals can be followed.

Summary
The results of measurements of height and weight made on 2,169 men, mainly office workers, attending a public health exhibition in the City of Londo have been analysed. Heights were similar to those reported from several other recent studies and thes showed a gradual decline with age, indicating a continuing secular increase in stature of just over $1 \mathrm{~cm}$ per decade. After standardizing for height, weight increased steadily with age up to age 50 , and declined a little beyond that. In contrast with the results from another recent study, differences in weights between non-smokers, ex-smokers, and smokers were small and not significant.

We are indebted to the Corporation of the City of London for providing facilities for this study, and to Dr. W. G. Swann, Medical Officer of Health, Port and City of London, Dr. D. T. Jones, and other members of the staff of the Public Health Department for their encouragement and assistance. We also wish to acknowledge the help and encouragement of the Director of the Air Pollution Unit, Professor P. J. Lawther. Other members of the staff of the Unit helped with the field work and gave valuable comments on the analysis of the results and the manuscript of this paper: much of the computer analysis was done by Mrs. Margaret Holmes. We are also indebted to Professor C. R. Lowe for many helpful comments.

\section{REFERENCES}

Ashford, J. R., Brown, S., Duffield, D. P., SMith, C. S., and FAY, J. W. J. (1961). The relation between smoking habits and physique, respiratory symptoms, ventilatory function, and radiological pneumoconiosis amongst coal workers at three Scottish collieries. Brit. J. prev. soc. Med., 15, 106. 
BJELKE, E. (1971). Variation in height and weight in the Norwegian population. Brit. J. prev. soc. Med., 25, 192.

BENN, R. T. (1971). Some mathematical properties of weight-for-height indices used as measures of adiposity. Brit. J. prev. soc. Med., 25, 42.

Brooks, A. G. F., and Waller, R. E. (1972). Peak flow measurements among visitors to a public health exhibition. Thorax, in press.

Howell, R. W. (1971). Obesity and smoking habits. Brit. med. J., 4, 625.

Khosla, T., and Lowe, C. R. (1967). Indices of obesity derived from body weight and height. Brit. J. prev. soc. Med., 21, 122.

$\longrightarrow$, and —. (1968). Height and weight of British men. Lancet, 1, 742.

- and - (1971). Obesity and smoking habits. Brit. med. J., 4, 10.
LAwther, P. J., Brooks, A. G. F., and WAller, R. E. (1970). Respiratory function measurements in a cohort of medical students. Thorax, 25, 172.

Lowe, C. R. (1971). Personal communication.

Pincherle, G. (1971). Obesity and smoking habits. Brit. med. J., 4, 298.

Richardson, J. F., and Pincherle, G. (1969). Heights and weights of British businessmen. Brit. J. prev. soc. Med., 23, 267.

Stoudt, H. W., Damon, A., McFarland, R., and RoBerTS, J. (1965). Weight, Height and Selected Body Dimensions of Adults. PHS Publication No. 1000, Series II, No. 8. U.S. Government Printing Office, Washington.

ToDD, G. F. (1969). Statistics of Smoking in the United Kingdom. Research Paper 1, 5th ed. Tobacco Research Council, London. 